\title{
The Ultimate Impacts for Thai Teachers: Teachers Development System in Learning Management
}

\author{
Thikamporn Boonmak ${ }^{1}$, Kowat Tesaputa ${ }^{1} \&$ Amparn Duangpaeng ${ }^{2}$ \\ ${ }^{1}$ Faculty of Education, Mahasarakham University, Thailand \\ ${ }^{2}$ Faculty of Education, Udon Thani Rajabhat University, Thailand \\ Correspondence: Thikamporn Boonmak, Faculty of Education, Mahasarakham University, 44000 Thailand. Tel: \\ 66-043-721-764. E-mail:thikamporn.boonmak@gmail.com
}

Received: May 29, 2015 Accepted: July 1, 2015 Online Published: November 26, 2015

doi:10.5539/ies.v8n12p193 URL: http://dx.doi.org/10.5539/ies.v8n12p193

\begin{abstract}
This research was aimed to 1) study current conditions, problems, and needs of teachers for development and learning management in the extended educational opportunities schools (EEOSs: schools where they extended fundamental education from primary level of six years to lower secondary level of nine years), in Thailand, 2) develop the system of teacher development for the learning management, 3) implement and extend the results of study to other EEOSs. Research methodology was based on research and development approach which divided into three stages as follows: Stage 1) Preliminary study on current conditions, problems, and needs from related literature. The synthesis of related ideas and theories were then validated by the survey on the subjects representing school administrators and academic affairs teachers. Statistics used were percentage, means, and standard deviation. Stage 2) System development for the learning management was validated by nine educational experts. The validity of the system was based on feasibility and content appropriateness. Stage 3) Implementation of the system. The school performed teacher development program according to the procedures described in the manual. There were five research tools used which included: data survey, semi-structure interview, knowledge evaluation, learning management competency evaluation, and satisfaction evaluation. Research finding reported that the teachers needed professional development on professional training, study visit, and internal supervision. The system of teacher development has four main factors: input, process, output, and feedback. Overall, the system was the standard baseline for effective training in the EEOSs and possible to implement in other schools for learning management and student effectiveness.
\end{abstract}

Keywords: teacher development system, learning management, extended educational opportunities schools

\section{Introduction}

\subsection{Importance of Teachers Development}

Teacher is the main factor contributing to educational quality development. The nation can be developed from the responsibility of teacher. As the Office of Educational Reform (2001) stated, teacher has a crucial responsibility because this related to cultivation of students' knowledge, attitude, and morality. It can be said that students are one of the most contributors to the nation's future. In addition, the National Education Act 1999 foresees that teachers are the key factors in educational reform and development. It is suggested that teaching professional development requires systematic support and process to evaluate its effectiveness since it affects the excellence and standard of advance career (Ministry of Education 2009). Teacher development is the important strategy to enhance professional. Teacher will be able to perform tasks with effectiveness and create learning experience with efficiency. This impact will be resulted in fully developed students. It is needed that development of teacher professional should incorporate the process in enhancing of knowledge, ability, and attitude. All of these are the main contributions for teacher performance. Students are also benefit from developed teachers in terms of mind, body, and social interaction (Udom, 2013; Mongkolwanich, 2012).

\subsection{Current Problems in Teacher Development in Thailand}

Problems in teacher development yet existed and needed to be investigated. The Bureau of Educational Council Secretary (2010) reported that the EEOSs were facing problems in students' academic performance, creative thinking, and academic acquisitive mind. It was found that teachers influence contributed the most to the above 
mentioned failures. In fact, teachers contribute impact to students by delivering their attributions to the students through the process of instruction. This is the crucial element of the learning process in educational management (Chiangkul 2006). As Nakhonthap (2003) studied, instructional problems in Thai's educational system were based on teaching styles which rote memorization was heavily employed. Teachers tended to lecture on the content rather than the learning process. Child-centered approach was not well-accepted among teachers. Students were found limited ability in problem solving skills, analytical thinking, and synthetic skills. Since the opening of opportunities would enhance their competency for fully developed capacity, teaching and learning environments that support students' opportunity to explore would lead to systematic thinking, social responsibility, and leadership. It was concluded that the quality of learning outcome is involved with the quality of teachers who are the mentors for students' quality (Intaraprasit, 2003).

Educational management needs to concern to the problems in instruction and to understand different learning styles. Since students come from various backgrounds, different interests, abilities, and needs; teaching needs appropriate approach for the expected results. It can also bring positive transition from ignorance to achievement, from inability to ability, and from dislike to preference. Learning can be successful by bringing the changes of behavior. The Office of Educational Certification and Quality Appraisal revealed that Thai teachers still lack of standard in teaching management. They tend to emphasize on content rather than critical thinking process. The core objectives as stated in the national curriculum yet not achieved. Also, the National Education Act emphasized repeatedly on professional teacher which required teachers' training on professional development to stimulus students' skills in application of knowledge for daily life. As a result, Thai students will be able to grow up completely as the well-balanced citizens. Every stakeholder such as parents, teachers, public sector administrators, and private sector entrepreneurs are all responsible for educational development. Students have to be well-balanced in all aspects to live in the society both inside educational institute and outside in the social organization. They should be the ideal citizens who well-equipped with attitude and value of self-development (Rutcharoun, 2011).

\subsection{Described Relevant Scholarships}

Teaching is the process of experience that students are not only the ones who receive but also interact with the process. Teachers need to enhance their teaching approach to be the knowledge construction teaching process. It requires personal mastery of individual teacher to be able to justify the way of teaching formula (Khamanee, 2012). Therefore, the management of learning and teaching is involved with experiential to relate them with authentic life experience. Student should interact with direct learning experience by observation, analysis, synthesis, operation, and summation. Learning outcomes are directly the results of appropriate combination of such elements. In the process of curriculum implementation, teachers need to be master in developing students' experiences to be the life-long learners. Teachers also have to respond to individual student's attributes such as personal ability, basic knowledge, and learning style according to each one. Teachers should consider appropriate evaluation method of learning outcome by students' performance compared with core objectives and local context (Thaipanich, 2003).

Teacher development is crucial in the following aspects: social, knowledge, competency, cognitive, operation, outcome, research, and emotion. These elements responsible for teachers' performance to have attitude and behavior for their professional and students' development (Borich, 1977; Hall \& Jores, 1976; Udom, 2013). Professional teachers need to consider development of the learning management. They have to know how to manage problems occurred in the classroom. The challenge of classroom problems would be opportunity for teachers to develop their teaching (Pornkul, 2008). Teachers are suggested to adopt appropriate strategy in their professional. Options for teaching strategy are included: theory, concept, idea, or strategic plan that appropriate with school context, students competency. Selected option will be able to operate effectively in well-designed lesson plan and teaching techniques (Dechakup, 2008).

\subsection{Stated Research Design}

As mentioned above, the researcher, who was responsible as the teacher in the EEOS, wished to study the development of teachers in order to formulate the system of learning management for implementation in most schools throughout the nation. This model of the system would be the guideline to solve educational problem and development of knowledge. Ultimately, the schools could be benefited in curriculum achievement as their goals have stated. Therefore, the research objectives were stated as the followings:

1) To study the current conditions, problems, and needs of teachers in learning management for the extended educational opportunities schools (EEOSs).

2) To develop the system of teacher development in learning management in the EEOSs. 
3) To investigate the results from system implementation in the EEOSs for its efficiency in learning management.

\section{Research Methodology}

\subsection{Identified Subsections}

The stages of operation were covered three main stages:

Stage 1: Preliminary Study. In this first stage, the researcher studied the primary sources of information related to current condition in learning management, current problems, and needs of teachers for their professional development. The study then was the basis for the theoretical framework to develop the preliminary questionnaire. In the same time, researcher studied teachers on their needs in professional training and educational management in the EEOSs.

Stage 2: System Development. This stage was aimed to investigate possible ways in development of the model. Two sub-stages were drafting of the system and validating of its possibility. In the first one, researcher drafted the manual of teacher development program for using in the training sessions. Specific context on the EEOSs was emphasized to be used in Thailand school system. The second one was the validating of its possibility to be implemented. The major advisor and education specialists were suggested to modification of the system model. Plan of system operation was suggested to execute in six steps: 1) knowledge construction, 2) actual operation, 3) knowledge sharing, 4) development, 5) supervision, following-up, and suggestion, and 6) operational feedback.

Stage 3: Operation on the EEOSs. After the model was well polished, researcher took it to implement for actual operation. The first step was to select one of the EEOSs to demonstrate as the manual suggested finding its effectiveness. Final step was related to analysis and presentation of operation's result from that school. This showed the training system's best practice to the public.

\subsection{Participant Characteristics and Research Tools}

Research and development approach was employed as the main process of research design. Areas and subjects were included school administrators and teachers responsible for academic affairs in the EEOSs. Total population were 586 subjects. There were two types of research tools which covered operational development tools and data collection tools. The first category was included manuals in operation for learning management and teacher development. Whereas the second category included tools of data survey, semi-structure interview, knowledge evaluation, learning management competency evaluation, and satisfaction evaluation. Statistics used were percentage, mean, and standard deviation.

\subsection{Sampling Procedures}

Total population was included school administrators and academic affairs teachers for 14,192 subjects from 7,096 EEOS schools in Thailand. The samplings were selected by the Multi-stage Sampling Method for 586 subjects from 293 schools. All sampling were categorized by geographic regions: Northern, Central, Northeastern, and Southern. Each region consisted of different provinces by using 30\% portion to select the number of provinces. In each province, the sample schools were selected randomly by using $15 \%$ portion to collect data in the schools. Data collection packages were distributed to 586 subjects in 293 schools but the responses were returned from 550 subjects in 275 schools at $94 \%$ response rate. 
Table 1. Population and sampling

\begin{tabular}{|c|c|c|c|}
\hline Region & Province & $\begin{array}{c}\text { Schools } \\
\text { Population }\end{array}$ & $\begin{array}{c}\text { Schools } \\
\text { Sampling Subjects }\end{array}$ \\
\hline \multirow[t]{5}{*}{ Northern } & Chieng Mai & 228 & 34 \\
\hline & Prae & 59 & 8 \\
\hline & Uttaradit & 61 & 9 \\
\hline & Pitsanulok & 163 & 24 \\
\hline & Kampaengpetch & 98 & 15 \\
\hline \multirow[t]{8}{*}{ Central } & Nakhonprathom & 41 & 16 \\
\hline & Nonthaburi & 25 & 4 \\
\hline & Pratumthani & 51 & 8 \\
\hline & Lopburi & 74 & 11 \\
\hline & Samutsongkram & 15 & 2 \\
\hline & Pracheanburi & 59 & 9 \\
\hline & Cholburi & 74 & 11 \\
\hline & Petchburi & 42 & 6 \\
\hline \multirow[t]{6}{*}{ Northeastern } & KhonKaen & 256 & 38 \\
\hline & Nakhonpanom & 78 & 12 \\
\hline & Yasothon & 96 & 14 \\
\hline & Nongkhai & 46 & 7 \\
\hline & Nongbualumphu & 83 & 12 \\
\hline & Udonthani & 230 & 35 \\
\hline \multirow[t]{4}{*}{ Southern } & Chumporn & 71 & 11 \\
\hline & Trang & 47 & 7 \\
\hline & Ranong & 28 & 4 \\
\hline & Satun & 42 & 6 \\
\hline Total & & 1968 & 293 \\
\hline
\end{tabular}

\section{Results}

The research results were categorized into three main stages: preliminary study, system development, and implementation of the system.

\subsection{Preliminary Study Was Divided in Three Sub-Areas Which Were}

1) Current conditions of teacher training. The results of the study were ranked from the most to the least accordingly. They showed interests on objective formulation, feedback of the data, organizing of learning activity, content design, data evaluation, student characteristics survey, and learning goals formulation.

2) Current problems were found accordingly from these rankings: feedback of the data, objective formulation, student characteristics survey, objective formulation, content design, organizing of learning activity, and data evaluation.

3) Teacher needs were found accordingly from these rankings: objective formulation, data evaluation, student characteristics survey, content design, feedback of the data, organizing of learning activity, and objective formulation. The summary of teachers' need in development was ranked from professional training (17.96\%), study visit (15.67\%), and supervision (13.49\%). 


\subsection{System Development}

The initial step was to develop the system of teacher training and manual of training procedures. Operation of training was 180 days or in 6 weekly training sessions. Activities encouraged knowledge management, understanding of learning management, and training for mastery. The expected results were to enable the trainees to implement the skills learned from training to their schools. The program included two kinds of activity on training and supervision. Process of training system was run on the PDC cycle which represented Plan, Do, and Check. Planning involved with preparation of manual and training procedures. Doing was actual operation according to the steps designated. This was the crucial part of the system because there were seven activities of training to develop the teachers. They exchanged their knowledge during the session along with the action of manual. Checking involved with revision of actions in accordance with procedures and objectives. The initial model might have effectiveness in some aspects while the others needed improvement plan.

The content of teacher development manual was divided into five chapters.

Chapter 1: Introduction, Rationale, Objectives, Goals, and Definition of key terms

Chapter 2: Introduction to the system of teacher development in the EEOSs

Chapter 3: The system of teacher development in learning management. This manual described elements of the training module, how the system operated, the detail operational plan, activities involved with the training sessions, and identification of system evaluation.

Chapter 4: System Implementation. This section described the PDC cycle in which the operation can perform.

Chapter 5: Testing and Evaluation of Operation. This section consisted of four tests which were: evaluation on knowledge of teachers on learning management, evaluation of competency in teaching management, evaluation of student satisfaction on teachers teaching, and evaluation of teacher satisfaction after implementation of the system.

\subsection{Implementation Results}

For the implementation of the system, it found that the management of learning in the EEOS had improved as the following areas.

1) Learning management in terms of current conditions, problems, and needs in training were overall required in high level as described in the following tables. The criteria for mean interpretation was categorized as extremely high when the mean is ranged from 4.51-5.00, high when the mean is ranged from 3.51-4.50, moderate when the mean is ranged from 2.51-3.50, low when the mean is ranged from 1.51-2.50, and extremely low when the mean is ranged from $1.00-1.50$.

Table 2. Overall current conditions of teacher development

\begin{tabular}{lll}
\hline Areas of current conditions & Mean & S.D. \\
\hline Rank1: objective formulation & 3.84 & 0.85 \\
Rank 2: feedback of the data & 3.84 & 0.85 \\
Rank 3: organizing of learning activity & 3.81 & 0.85 \\
Rank 4: content design & 3.72 & 0.88 \\
Rank 5: data evaluation & 3.69 & 0.85 \\
Rank 6: student characteristics survey & 3.67 & 0.88 \\
Rank 7: learning objective formulation & 3.63 & 0.88 \\
\hline
\end{tabular}

From Table 2, it found that current conditions of teacher development were aiming toward object formulation and feedback. Objective formulation is relevant to collaboration of teachers in setting up goals to meet learners' needs. School administrators have to provide teachers with consultation in objectives formulation that emphasized on knowledge, cognitive skills, academic attitude, and ideal characteristics. In addition, feedback of the data could be established through organization of planning for the teachers to prepare evaluation tools on different content areas. Moreover, the process of educational supervision by the administrator and peer supervision is the way to enhance feedback. The data from feedback has to be current and accessible. 
Table 3. Overall problems of teacher development

\begin{tabular}{lll}
\hline Areas of problems & Mean & S.D. \\
\hline Rank1: feedback of the data & 3.84 & 0.85 \\
Rank 2: learning objective formulation & 3.40 & 1.06 \\
Rank 3: student characteristics survey & 3.35 & 1.08 \\
Rank 4: objective formulation & 3.26 & 1.10 \\
Rank 5: content design & 3.25 & 1.13 \\
Rank 6: organizing of learning activity & 3.20 & 1.21 \\
Rank 7: data evaluation & 3.19 & 1.12 \\
\hline
\end{tabular}

From Table 3, the top rank problem in data feedback was from the lack of appropriate system to organize the information. Since data was scattered throughout departments and people, teacher development in MIS (Management of Information System) is required. Some forms of MIS such as portfolio, best practice showcase, and focus group.

Table 4. Overall needs of teacher development

\begin{tabular}{lll}
\hline Areas of needs & Mean & S.D. \\
\hline Rank1: learning objective formulation & 4.23 & 1.43 \\
Rank 2: data evaluation & 4.14 & 1.39 \\
Rank 3: student characteristics survey & 4.11 & 1.40 \\
Rank 4: content design & 4.10 & 1.37 \\
Rank 5: feedback of the data & 4.03 & 1.40 \\
Rank 6: organizing of learning activity & 4.01 & 1.37 \\
Rank 7: objective formulation & 3.96 & 1.39 \\
\hline
\end{tabular}

From table 4, learning objective formulation seemed to be the first priority in teacher development. Schools were better to clarify core policy in learning management. Collaborative planning was recommended to allow teachers in all departments to formulate learning objectives of the whole school to meet policy. The follow-up by supervision procedures would ensure how objectives were achieved.

Overall opinions of the administrators and teachers in their needs in learning management training were reported that they preferred training session for professional development (17.96\%), study visit to other EEOSs with best practice (15.67\%), and supervision from related personnel (13.49\%) respectively.

2) Factors of the system in teacher training for learning management in the EEOSs. There were four main factors which included: Input, Process, Output, and Feedback. First, the Input factors included: administrators, teachers, students, core curriculum, mentors, learning environment, budget, and technology. Second, the Process factors included: objective formulation, student characteristics survey, learning objective formulation, content design, organizing of learning activity, data evaluation, and feedback of the data. Third, Output factors included: teacher knowledge in learning management, ability in learning management, and student satisfaction to the teachers. Fourth, the Feedback factors included: data report after implementation, suggestion from various stakeholders, and modification of the model. 


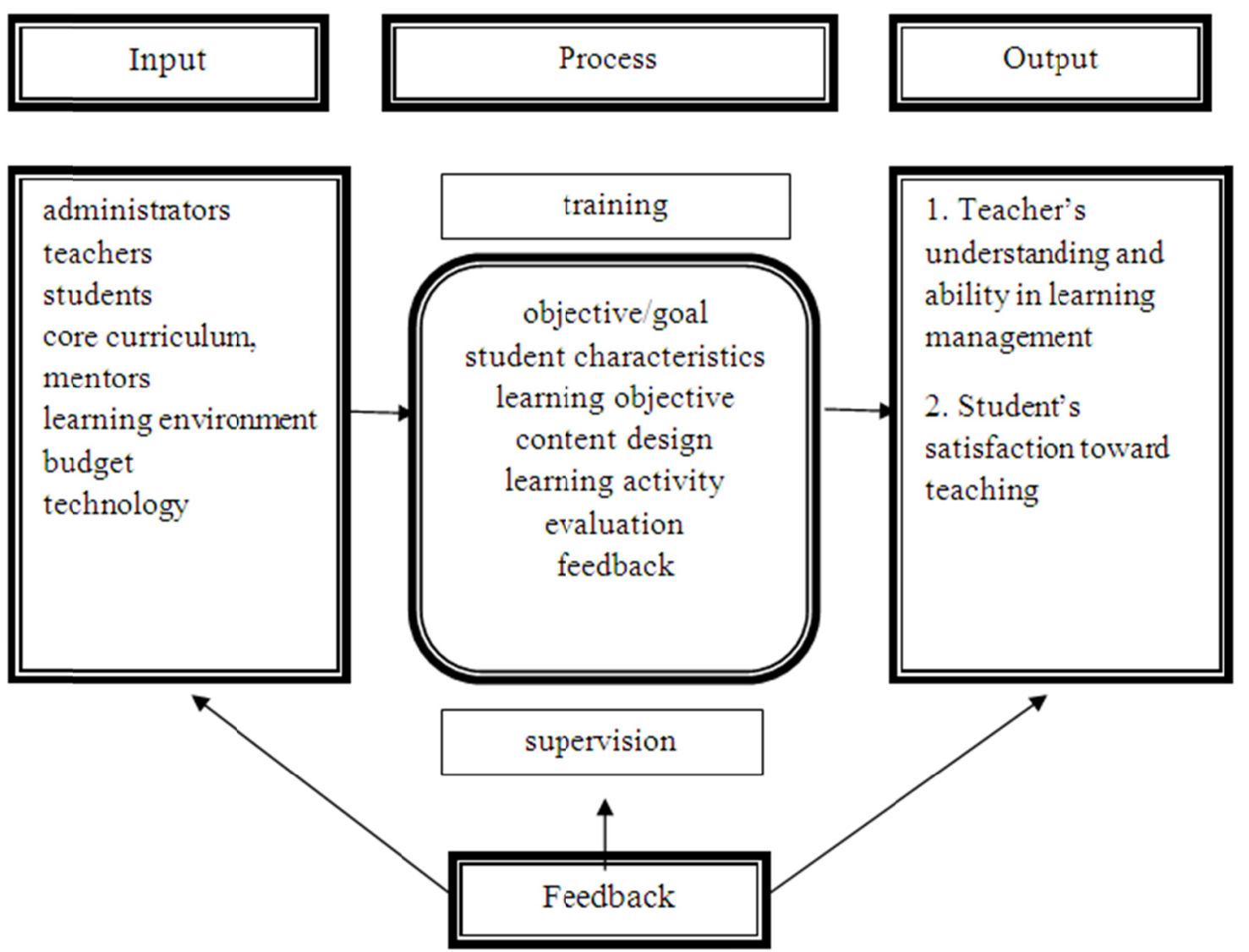

Figure1. System model in teacher training for learning management in the EEOSs

\section{Discussion}

The research on the development of the training system for learning management had revealed issues worth for discussion as the following aspects: current conditions, system development, and implementation effectiveness.

I) Current conditions of the management in teacher development was overall ranked in high level which consistent to the needs in professional development, while the problems in teacher development was still in the moderate level. The reason that explain this relationship between needs and problems was that most teachers aware of the system of development but they lacked of the system of development. More attention in developing programs for teacher training by the supervision sectors was highly needed. In addition, Suthornrote (2004) has proved that a school in Thailand had adopted child-centered approach into their teacher development and it enhanced teachers to aware of students' need. Therefore, they can develop teaching approach in accordance to students' preference through instruction and materials that specially developed. Also, Thongsaen (2010), has adopted the development program for her mathematics course in accordance with math teacher professional standards. She found that the model employed to her students brought them with more confidence, positive attitude, and math skills. Another development study by Duangkhamnoi (2011) which revealed that the system of student counseling enhance teachers with more understanding in students' problems investigation, prevention, and solution. Teachers can develop effective roles in preference student characteristics. The problem in educational management was not ignored to investigate by the Ministry of Education. In 2010, the Bureau of Educational Council Secretary found problems in primary education management, students learning outcomes, and development of teacher professional. It found that most primary school teachers lacked of knowledge in curriculum which resulted from insufficient supervision authorities to develop the ways to evaluate their teaching performance. Students posed the lower-standard in academic performance, preference learners characteristics, analytical thinking, problem solving skills, and creative mind. Teacher professional development was affected from restructuring of school system and administration which found by insufficient numbers of teacher employment in many levels and academic departments. Moreover, education system could not attract 
high proficiency people to be teachers.

School should be developed to be the learning organization. As Lovett (2002) stated, teachers in schools can develop the way in learning with more alternative approaches and they should revise learning outcome. School is the learning center with the potential people who are the developers of learning community. School can transform to be a learning organization with appropriate current management. Doran (1994) suggested that teacher reflection was the approach to develop professional by allowing chances to reflect experience that someone occupied. The variety of reflection allowed teachers to express their goals and ways to delivers expected outcomes to the student.

II) System development for learning management in the schools was consisted of factors of Input, Process, Output, and Feedback which were described earlier in the model. Additionally, Chooratsakcharoen (2007) suggested the learning system based on local wisdom. There were eight steps to follow: 1) study local conditions and needs, 2) formulate philosophy and mission, 3) state policy, objective, and goal, 4) analyze the content, 5) specify local wisdom, 6) design learning lesson based on local wisdom, 7) operate to the lesson plan, and 8) evaluation and follow-up the result. Soypechkasem (2004) studied four main elements of learning management process which were: 1) evaluation objectives, 2) construct of evaluation, 3) method of evaluation, and 4) criteria of evaluation. While Pliankham (2007) found similar direction for teacher development elements which included: 1) direction of development - the main core and objective of development, 2) process of development knowledge to be used, know to develop, what activity to conduct for group and individual, procedures in operation, media to assist learning, and staff to responsible for development, 3) evaluation - the process of evaluation and the process of following-up the results.

III) Implementation of the teacher development system in the EEOSs enhanced the efficiency of the teachers. The development of system model included seven elements: objective/goal setting, evaluation of student characteristics, formulating of the learning objective, consideration of content design, manipulation of the learning activities, validate effectiveness by evaluation process, and examination of program by observing the feedback. From the results, teacher showed improvement in learning management knowledge and more awareness in learning management. Teachers could bring the skills to implement in the schools which yielded students' satisfaction toward new approach. Moreover, the school administrators also show positive feedback by observing the child-centered approach in development of teaching. The skills were directly learned from training and internal supervision.

The implementation of teacher development was also widely studied. In Phaijjitthanachot (2005), reported that three methods in training were short course program, apprentice practice for skills development, and training for career specialization. Whereas Chuenprapanusorn (2011) observed efficiency of teachers after the training sessions. They showed improvement in academic area, learning management, and evaluation. Skills of teaching and attitudes were also tended to the positive direction. Kuna-abhisit (2004) studied the program for teacher development in the secondary education level and found that the effective program included three main stages: training and operation session in the schools, supervision session after the training, and conference on summary of practice and reflective evaluation. These stages could enhance teacher knowledge and attitudes. While in small-size school, Samart (2011) found that commitment on mission was the key success factor in teacher development. They had shared value in development and performance by constructing the network. In addition, school administrators have influence on teacher development for the activity of training, study visit, educational advancement, and self-development (Chat-ngern, 2007). The network of teachers is crucial for professional development. As suggested in Wisalaporn (2002), there were different strategies in development such as professional training, research studies, study visit trip, and academic conference. These opportunities were the effective strategies to allow teachers develop their career vision. Also, the system of mentoring, counseling, coaching, and extended education were helpful for teacher network.

\section{Suggestions}

The research provided suggested implementation to different sectors which this training system would be suitable for them. In order to be effective in the schools, it is suggested that:

1) The Office Area of Primary Education to carry the results of the research for implementation of training sessions by specific subjects/department. The Office should organize the conference for teachers in the educational area to exchange experiences and discuss for the effective results in learning management.

2) Schools to summarize the result of evaluation by different departments to reflect the overall performance of the schools. Administrators should assign weekly report of the progress and students performance from the teachers who passed the training. Yet schools should establish support system such as teacher network, training 
coaching and mentoring for effective results.

3) Teachers to adjust their classroom management with relationship to the content of training manual and current conditions. They should be allowed to access to training opportunity for learning management.

4) Future researchers to apply the research methodology over other type of schools besides the EEOSs. The areas of study could be more focused on the sub-factors in the system. However, this research was the experimental studies to investigate the impact on teacher development system. It is suggested to apply the process of operational research on other size of schools apart from this study.

\section{References}

Borich, G. (1977). The Appraisal of Teacher: Concept and Process. Reading, MA: Addison-Westley.

Bureau of Educational Council Secretary. (2010). Research and Development on Policy of Teacher Development. Bangkok, Thailand: Prickwan Graphic.

Chat-ngern, W. (2007). Roles of School Administrators in Teachers Development: The Case Study of the Primary Schools in KhaoKichagood District, Chantaburi Province (Unpublished master's thesis). Burapha University, Cholburi, Thailand.

Chiangkul, W. (2006). Thailand's Educational Conditions during 2006-2007: Problem and Solution. Bangkok: VCT Communication.

Chooratsakcharoen, N. (2007). Design of Instructional System Based on Local Wisdom: The Case Study on Handicraft Subjects for Primary Students in Grade 4-6 in Bangkok Metropolitan Schools (Unpublished master's thesis). SukhothaiThmmathirat Open University, Bangkok, Thailand.

Chuenprapanusorn, T. (2011). The Development of Model English Teacher for Teaching Communicative English in Kindergarten: The Case Study in Students of Suan Dusit Rajabhat University. Bangkok, Thailand: Suau Dusit Rajabhat University Press.

Dechakup, P. (2008). 5C Skills for Learning Unit Development and Standard Learning Management. Bangkok, Thailand: Chulalongkorn University Press.

Doran, M. L. (1994). A Story of Professional Development: Teachers' Learning from Reflective Experiences (Doctoral dissertation). University of Michigan. Retrieved from http://deepblue.lib.umich.edu/handle/2027.42/104245

Duangkhamnoi, S. (2011). Teacher Development on Student Counseling System: The Case Study of PhonNgamWittayanukul, Mahasarakham Province (Unpublished master's thesis). KhonKaen University, KhonKaen, Thailand.

Hall, G. E., \& Jores, H. L. (1976). Competency-based Education: A Process for the Improvement of Education. New Jersey: Prentice Hall.

Intaraprasit, M. (2003). Learning Process Revolution for Mathematics Teaching in School. KhonKaen, Thailand: KhonKaen Publishing.

Khamanee, T. (2012). Teaching Pedagogy for Effective Learning Management. Bangkok, Thailand: Chulalongkorn University Press.

Kuna-abhisit, W. (2004). Development of Model for Teacher Development in the Health Education and Physical Education Department (Unpublished doctoral dissertation).Chulalongkorn University, Bangkok, Thailand.

Lovett, S. (2002). Teacher Learning and Development in Primary Schools: A View Gained through the National Education Monitoring Project (Doctoral dissertation). University of Canterbury, New Zealand. Retrieved from http://ir.canterbury.ac.nz/handle/10092/1049

Ministry of Education. (2009). National Education Act. Bangkok, Thailand: Teacher Council Press.

Mongkolwanich, C. (2012). Management of Educational Organization and Personnel. Bangkok, Thailand: Chulalongkorn University Press.

Nakhonthap, A. (2003). Annual Report of Thai Education in 2003. Bangkok, Thailand: Phappim Publishing.

Office of Educational Reform. (2001). Standard of Teacher Professional. Bangkok, Thailand: The Office of Educational Reform.

Phaijjitthanachot, N. (2005). Model for Teacher Development Program in Occupational and Technological Department of Schools Network in ChulabhornRajawittayalai School (Unpublished dissertation). Naresuan 
University, Pitsanulok, Thailand.

Pliankham S. (2007). Model for Teacher Development in the Health Education and Physical Education Department (Unpublished dissertation). Chulalongkorn University, Bangkok, Thailand.

Pornkul C. (2008). Teaching Design for Integration of Reading, Analytical Thinking, and Writing. Bangkok, Thailand: Chulalongkorn University Press.

Rutcharoun, T. (2011). Strategy to Develop the Learning Individual. Bangkok, Thailand: Khao Fang Publishing.

Samart, S. (2011). Program for Teacher Development in Small Schools (Unpublished dissertation). KhonKaen University, KhonKaen, Thailand.

Soypechkasem, C. (2004). Development Model in Appraisal of Learning Process in the Schools in the Basic Education Commission (Unpublished dissertation). Naresuan University, Phitsanulok, Thailand.

Suthornrote, W. (2004). Teacher Development in Learning Management based on Child-centered Approach. Mahasarakham, Thailand: Mahasarakham University Press.

Thaipanich, W. (2003). Teaching Design and Development. Bangkok, Thailand: Ramkhamhaeng University Press.

Thongsaen, K. (2010). Teacher Development by Professional Mathematics Standards Using Lesson Plans (Unpublished dissertation). KhonKaen University, KhonKaen, Thailand.

Udom, P. (2013). Cause and Effect Analysis of Teacher Proficiency Development of the Southern Teachers by the Professional Standard Criteria in Learning Management. NakhonSrithammarat: Thaksin University Press.

Wisalaporn, S. (2002). Research Report of Network Model for Teaching Professional Development by the National Educational Act B.E. 2524. Bangkok, Thailand: The Office of Government Official Teachers.

\section{Copyrights}

Copyright for this article is retained by the author(s), with first publication rights granted to the journal.

This is an open-access article distributed under the terms and conditions of the Creative Commons Attribution license (http://creativecommons.org/licenses/by/3.0/). 